\title{
EFFECTIVE MARGINAL TAX RATES FOR WORKING FOR FAMILIES RECIPIENTS
}

\author{
Philip Spier \\ Centre for Social Research and Evaluation \\ Ministry of Social Development
}

\begin{abstract}
This paper examines how the Working for Families (WFF) package changed work incentives for WFF recipient families. While not being able to examine work incentives directly, we were able to measure changes in effective marginal tax rates (EMTRs) for WFF recipients. The lower the EMTR a person faces, the more financially profitable it is for them to increase their hours of work or earnings. Conversely, a high EMTR over a range of earnings can be a disincentive for a person to work more. Beneficiary families and the vast majority of low income non-beneficiary families in receipt of WFF had lower EMTRs as a result of the policy changes. The April 2006 changes to the WFF package decreased EMTRs for middle-to-high income families already in receipt of WFF Tax Credits, but increased EMTRs for families who became newly eligible for this component as a direct result of the changes.
\end{abstract}

This research on effective marginal tax rates (EMTRs) for Working for Families (WFF) recipients was conducted as part of a wider evaluation of the WFF package conducted by the Ministry of Social Development (MSD) and Inland Revenue (IR). For further details on findings from the evaluation see: http://www.msd.govt.nz/about-msd-andour-work/publications-resources/evaluation/receiptworking-for-families/index.html.

\section{What is Working for Families?}

The WFF package introduced changes to in-work incentives and family entitlements, and provided support to meet childcare and accommodation costs. The main components affected by the policy changes were WFF Tax Credits, the Accommodation Supplement (AS) and Childcare Assistance (CCA), all of which existed in some form before WFF. The major changes began in October 2004 and were implemented in stages through to 1 April 2007. The key target group for the WFF changes were low-to-middle income families.

In the 2008 tax year, families received a total of $\$ 3.11$ billion from WFF Tax Credits, AS and CCA. ${ }^{1}$ Families in receipt of a main benefit (eg the Unemployment Benefit or Domestic Purposes Benefit) received $\$ 1.15$ billion in 2008, while non-beneficiary families received $\$ 1.95$ billion. The amount of WFF dollars paid to individual families is determined by a number of factors including: total family income, the sources of income, and the number and ages of dependent children.

\section{What are the objectives of WFF?}

The key objectives of the policy changes set out by Cabinet in 2004 were to:
- make work pay by supporting families with dependent children, so that they are rewarded for their work effort

- ensure income adequacy, with a focus on low and middle income families with dependent children to address issues of poverty, especially child poverty

- achieve a social assistance system that supports people into work, by making sure that people get the assistance they are entitled to, when they should, and with delivery that supports them into, and to remain in, employment.

\section{What are effective marginal tax rates?}

Income a person earns from employment is subject to income tax. However, this may not be the only part of their earned income that is lost to the person. Workers pay Accident Compensation Corporation (ACC) levies on liable income earned, and people receiving social assistance face abatements (a reduction in entitlements) when they earn income above specified thresholds. ${ }^{2}$ Additionally, people may have obligations to repay Student Loans to the government, or to pay Child Support for their children no longer living with them.

EMTRs are a measure of the total amount lost from a marginal increase in earnings (often taken to be \$1) due to taxes, deductions and social assistance abatements. For example, an EMTR of $60 \%$ means that $60 \notin$ of the next $\$ 1$ of income earned is lost to the person, and $40 \varnothing$ is kept in the hand. 


\section{Why are we interested in EMTRs?}

The WFF dollars paid have improved income adequacy for many recipient families. WFF payments are successfully reaching the policy's target groups, and have reduced the income gap between high income and low income households (Ministry of Social Development and Inland Revenue, 2010). There have also been improvements to child hardship rates for the types of families targeted by WFF (Perry, 2009). There is also an interest in whether WFF has achieved one of its other objectives, of making work pay.

EMTRs are often used as an indicator of the financial incentive for individuals to earn additional income. The lower the EMTR a person faces, the more financially profitable it is for them to increase their hours of work or earnings. Conversely, a high EMTR over a range of earnings can be a disincentive for a person to enter the workforce, to increase their hours of work, or to take on higher paying employment, if the financial benefits are small (or negative).

From a wider perspective, there is also a large body of research which shows increasing EMTRs for large numbers of people has "serious negative consequences on economic growth, labour supply, and capital formation" (Karabegovic et al, 2004).

There is ongoing interest, therefore, in the levels of EMTRs faced by WFF recipients and, in particular, the number and types of families facing high EMTRs which may act as a disincentive for them to enter work or to extend their working hours.

It should be acknowledged there is some conjecture over the extent to which EMTRs influence individuals' decisions to increase their participation in work particularly in relation to the big changes in a person's employment behaviour, such as moving from not working or working part-time, to working full-time.

This report examines EMTRs in relation to a marginal increase in earnings of $\$ 1$ a week. In the context of WFF, this won't capture the impact on employment behaviour of those big decisions individuals and families make about whether to work or not, or whether to work parttime or full-time. A key aim of the WFF package changes, such as the introduction of the in-work tax credit, was to provide an incentive for beneficiaries with children to move from a benefit into part-time or full-time work. An EMTR analysis alone cannot adequately capture what things have an impact on people's workrelated decisions. Other factors, such as the availability of childcare or access to transport, may be far more important in decisions individuals and families make to increase their participation in work.

\section{How were EMTRs calculated?}

Using linked MSD and IR administrative data for the 2004 to 2008 tax years ${ }^{3}$, nine individual components were included in the EMTR calculation as contributing to an overall EMTR faced by WFF recipient families:

- Income tax

- ACC levies

- WFF Tax Credits abatement

- Accommodation Supplement abatement

- Childcare Assistance abatement

- Benefit abatement

- Student Allowance abatement

- Student Loan obligations

- Child Support obligations.

Components such as Student Loan and Child Support obligations are included to provide a clearer picture of the overall disincentives for families to increase their participation in work. While they are not 'taxes', they are legislatively-defined deductions that can contribute to high EMTRs.

EMTRs were calculated in relation to earning a theoretical extra $\$ 1$ a week (\$52 a year) of labour market income from the position the person was in at the end of each tax year. An overall EMTR for each person was calculated by summing all nine EMTR components, making some allowance for interacting components. For couples, the family EMTR was taken to be the highest EMTR faced by either person.

\section{Findings}

\section{What level of EMTRs do families ${ }^{4}$ face overall?}

Of the 357,200 WFF recipient families in the 2008 tax year" :

- $\quad 34 \%(122,800)$ had an EMTR of $25 \%$ or less

- $\quad 20 \%(71,600)$ had an EMTR between $25 \%$ and $50 \%$

- $\quad 35 \%(126,700)$ had an EMTR between $50 \%$ and $75 \%$

- $\quad 9 \%(30,800)$ had an EMTR between $75 \%$ and $100 \%$

- $2 \%(5,400)$ had an EMTR above $100 \%$.

Figure 1 shows EMTRs are different under WFF. Recipient families in $2008^{6}$ were more likely to face low EMTRs up to $25 \%$ and less likely to face very high EMTRs above $75 \%$ than before WFF was introduced. Some families have greatly improved EMTRs under WFF, while others face higher EMTRs. The pattern of EMTRs has also been affected by changes in the types of families being eligible to receive WFF at different times.

An abatement of a WFF main component contributed to the overall EMTR for less than half $(47 \%$ or 168,300$)$ of all recipient families in 2008. This is a considerably lower proportion than pre-WFF, when $72 \%$ of families in 2004 had an abatement of a WFF main component contributing to their overall EMTR. This decrease is largely a result of the removal, under WFF, of the AS abatement for beneficiaries. 
Figure 1: Overall EMTR profile in 2004 and 2008 for WFF recipient families

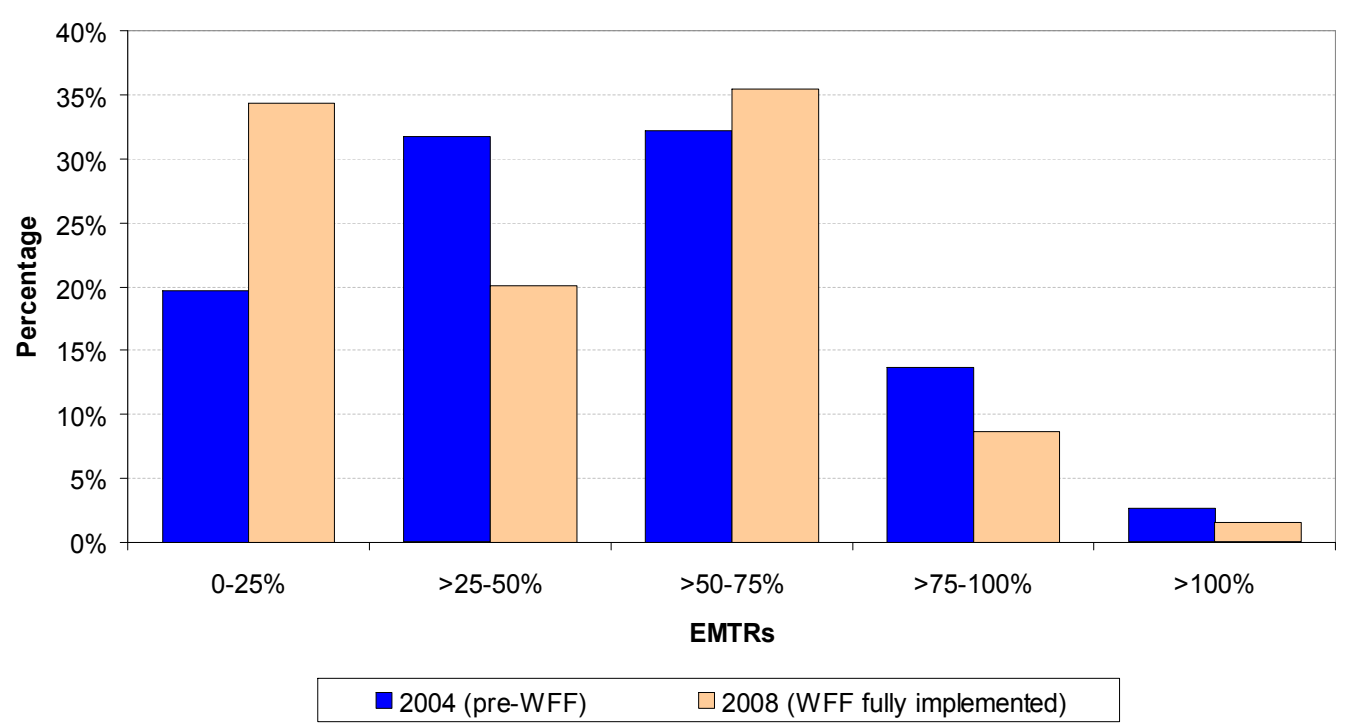

The average EMTR of families with children receiving WFF:

- decreased from $47 \%$ to $40 \%$ between 2004 and 2005 - reflecting the removal under WFF of the AS abatement for beneficiaries

- increased again by the time WFF was fully implemented due to the changed WFF Tax Credits abatement regime and expanded eligibility: by 2008 , the average EMTR was $45 \%$.

\section{How did WFF change the EMTRs for low income families?}

Two changes implemented as part of the WFF package reduced EMTRs for many low income families:

- from October 2004, beneficiaries in receipt of AS no longer faced an abatement of this component on the first $\$ 80$ they earned

- from April 2006, the adjustment to income thresholds and abatement rates for WFF Tax Credits meant families with annual incomes between $\$ 20,356$ and $\$ 35,000$ whose WFF Tax Credits were previously abating at $18 \%$ or $30 \%$, no longer faced any abatement of this component.

Beneficiary families have lower EMTRs under WFF because of these two changes - particularly the first one. In 2004, $71 \%$ of beneficiary families had an abatement of a WFF component contributing to their overall EMTR, but from 2007 none do. The average EMTR for WFF recipient beneficiary families dropped from $47 \%$ in 2004 to $22 \%$ in 2005 , and has remained at this lower rate.

The vast majority of beneficiaries not in paid work have low EMTRs, and only face EMTRs above 25\% when they have Student Loan or Child Support obligations. In contrast, beneficiaries in paid work face a wide spread of EMTRs - including 35\% $(19,800)$ in 2008 who faced EMTRs in excess of $75 \%$. Benefit abatement at the maximum rate of $70 \%$ was the primary cause of these very high EMTRs (on top of income tax and ACC levies).

Non-beneficiary families with very low incomes in receipt of the minimum family tax credit face total EMTRs just above 100\%. The April 2006 changes to the WFF package increased the after tax income threshold for this tax credit from $\$ 15,080$ to $\$ 17,680$. Subsequently, the number of families assessed as being eligible to receive the component more than tripled from 900 in 2006 to 2,800 in 2007.

Other low income non-beneficiary families in receipt of WFF Tax Credits, with annual incomes between $\$ 20,356$ and $\$ 35,000$, have much lower EMTRs following the April 2006 WFF changes.

How did WFF change the EMTRs for middleto-high income families?

Changes to the WFF package in April 2006 included: the introduction of the in-work tax credit; the replacement of two WFF Tax Credits income thresholds by a single higher threshold; and the removal of the $18 \%$ WFF Tax Credits abatement rate along with a reduction in the $30 \%$ rate to $20 \%$.

As a result of these changes, EMTRs for many middleto-high income families receiving WFF Tax Credits were lower due to a reduction in the abatement rate from $30 \%$ to $20 \%$.

However, approximately 50,000 non-beneficiary families became newly eligible to receive WFF Tax Credits as a result of the higher income thresholds associated with the in-work tax credit. These families 
had their overall EMTRs increased by $20 \%$ due to them now receiving WFF Tax Credits at an abated rate. Although they faced higher EMTRs, these families had disposable incomes greater than they would have been without the April 2006 changes.

\section{What are the characteristics of families with very high EMTRs?}

Ten percent $(36,100)$ of all WFF recipient families in 2008 had EMTRs above 75\%. This included 2\% $(5,400)$ who had EMTRs over $100 \%$. Families with EMTRs above $100 \%$ would initially lose money if they took on additional paid employment.

Of the 36,100 families facing very high EMTRs in 2008 - the majority $(19,800)$ were beneficiary families.

In the 2008 tax year, $17 \%$ of all WFF recipient beneficiary families faced EMTRs of more than $75 \%$. The proportion has been slightly lower since the introduction of WFF. Very high EMTRs for beneficiaries are primarily due to benefit abatement usually at the maximum rate of $70 \%$ (on top of income tax and ACC levies). Student Loan obligations (28\% of all WFF recipient beneficiary families in 2008) and Child Support obligations (10\% in 2008) also add to very high EMTRs for some beneficiaries.

Seven percent $(16,300)$ of all WFF recipient nonbeneficiary families had EMTRs above $75 \%$ in 2008 . Very high EMTRs for non-beneficiaries can be due to a single other component on top of income tax and ACC levies (such as minimum family tax credit), or can be due to the cumulative effect of numerous other components.

Very high EMTRs for non-beneficiaries almost always include the abatement of WFF Tax Credits and/or AS, along with income tax and ACC levies. This was also the case before WFF was introduced (for Family Assistance and AS abatement). Student Loan obligations $(31 \%$ of WFF recipient non-beneficiary families in 2008) and Child Support obligations (26\% in 2008) often also contribute to high EMTRs for nonbeneficiary families.

In 2008, 2,700 families (sole parents in $80 \%$ of the cases) were entitled to the minimum family tax credit. This component abates dollar-for-dollar of net family income so, in combination with income tax and ACC levies, recipients face EMTRs just above 100\%.

Very few recipients of Childcare Assistance face an abatement of the component on the next dollar earned only $0.1 \%$ (40) in 2008 . However, for the few families affected, on average they lost $\$ 22$ of their entitlement as a result of earning an extra $\$ 1$.

Of the 3,200 families with children who received the Student Allowance in March 2008, 27\% (900) had a dollar-for-dollar (100\%) abatement of part of the allowance, as their family income exceeded the allowable income threshold.

\section{How do EMTRs differ for primary and secondary earners in couple families?}

The EMTR faced by each person in a couple with dependent children is often different (this being the case for $80 \%$ of WFF recipient couples in 2008). Usually this is due to the couple having different earnings and therefore different personal tax rates. A person could also have a higher EMTR if they had, for example, Child Support obligations.

EMTRs were examined separately for primary earners (defined as the person in a couple who earns the most), and secondary earners (the person who earns the least). As may be expected, secondary earners generally have lower EMTRs than primary earners: $85 \%$ of secondary earners in 2008 had EMTRs below 50\%, compared to $43 \%$ of primary earners.

The average EMTR for primary earners in couples increased slightly after the April 2006 WFF Tax Credits changes (from $52 \%$ to $54 \%$ ), while the average EMTR for secondary earners decreased by 10 percentage points (from $46 \%$ to $36 \%$ ). As well as the effects of the April 2006 changes, these trends were influenced by the types of families becoming newly eligible for WFF Tax Credits from April 2006.

\section{Changes in EMTRs for families receiving WFF in 2008}

Eligibility rules for WFF Tax Credits have changed over time, so the types of the families receiving this component in 2008 are not the same as the families who received it in 2004. To take this into account, the EMTR profile of the families receiving WFF in 2008 were compared with the EMTR profile assuming the WFF changes had not been implemented for two groups - those who would have been eligible for WFF Tax Credits in 2004, and those who would not have been eligible.

Nearly two-thirds of the families who received WFF Tax Credits in 2008 would have been eligible for Family Assistance in 2004 based on their 2008 family incomes, sources of income and the number and ages of their children. The average EMTR for such families in 2008 was $24 \%$. If WFF had not been introduced, the families would have been facing considerably higher overall EMTRs of $52 \%$ on average. The lower EMTRs under WFF are mainly due to the removal of the AS abatement for beneficiaries, and changes to WFF Tax Credits income thresholds and abatements from April 2006. As well as having considerably lower EMTRs, these families were receiving greater amounts of WFF payments and had disposable incomes that were, on average, approximately $\$ 100$ a week more than they would have been without WFF. 
Over a third of the WFF recipient families in 2008 would not have been eligible for Family Assistance in 2004 because their family incomes were too high. The overall EMTRs of these families were $20 \%$ higher, on average, in 2008 than they would have been without WFF. This is due to them receiving WFF Tax Credits at an abated rate. While these families had higher EMTRs under WFF, they had disposable incomes that were, on average, approximately $\$ 120$ a week more due to the WFF payments they were receiving.

\section{What are the EMTRs for AS recipients without children?}

Most of the 125,700 recipients of AS in 2008 who did not have dependent children were either single beneficiaries (in $64 \%$ of cases) or single nonbeneficiaries (in 23\% of cases). Couples account for the remaining $13 \%$ of AS recipients without children. The majority of non-beneficiaries without dependent children receiving AS are superannuitants.

Seven out of 10 singles and couples without children receiving $\mathrm{AS}$ had low EMTRs of up to $25 \%$. In contrast, around one in 10 of them had EMTRs of more than $75 \%$ - typically from $70 \%$ benefit abatement, income tax and ACC levies.

The removal under WFF of the AS abatement for beneficiaries saw the average EMTR for all singles and couples without children receiving AS drop from 43\% in 2004 to $22 \%$ in 2005 , and it has remained at $22 \%$.

\section{Changes having an impact on EMTRs since the 2008 tax year}

At the time the analysis for this report was done, linked IR/MSD data was not available beyond the 2008 tax year. Since then, there have been changes to many of the nine components included in the EMTR calculations. There was also a new tax credit introduced in the 2010 tax year for non-beneficiaries not eligible for WFF Tax Credits - the independent earner tax credit (IETC).

Tax cuts (changes to tax rates and associated income thresholds) have lowered EMTRs by a few percentage points for many families - offset to a small extent by increases in ACC levies. An increase in the income threshold for WFF Tax Credits from October 2008 means some families will have EMTRs which are 20\% lower. In contrast, any families who became newly eligible for WFF Tax Credits as a direct result of the change will have higher EMTRs.

Increases to the income thresholds for some main benefits are expected to improve financial incentives for part-time work for those receiving such benefits. ${ }^{7}$

Recipients of the IETC with annual incomes above $\$ 44,000$ and up to $\$ 48,000$ will have EMTRs $13 \%$ higher due to the abatement of the tax credit.

\section{Conclusions}

The incentives for being in paid work have improved for most WFF recipient beneficiary families as a result of reduced EMTRs under WFF. The removal of the AS abatement for beneficiaries, and the April 2006 changes to the WFF Tax Credits income thresholds and abatement rules mean beneficiaries no longer face any WFF abatement.

Beneficiaries in paid work can, however, still face very high EMTRs primarily due to benefit abatement at $70 \%$ on top of income tax and ACC levies. In 2008, $17 \%(19,800)$ of all beneficiary families had EMTRs in excess of $75 \%$. For these families, work incentives may be low.

Non-beneficiary families with very low incomes receiving the minimum family tax credit had overall EMTRs just above $100 \%$. Work incentives are very low for such families unless they can start earning over the income threshold for this tax credit. When they do this, their EMTRs will fall considerably.

As expected $^{8}$, the April 2006 changes to the WFF Tax Credits income thresholds and abatement rules improved EMTRs for other low income working families, thereby improving their work incentives. Non-beneficiary families with annual incomes between $\$ 20,356$ and $\$ 35,000$, who previously faced an $18 \%$ or $30 \%$ abatement of their WFF Tax Credits payments, no longer faced an abatement of this component from April 2006.

An anticipated consequence of the WFF changes in April 2006 was that EMTRs would be higher for some middle and higher income families who became newly eligible to receive WFF Tax Credits as a direct result of the changes. Approximately 50,000 middle-to-high income families have greater disposable incomes from their new entitlements, but their work incentives have reduced as a result of an increase in their EMTRs due to the $20 \%$ WFF Tax Credits abatement.

\section{Notes}

1. This compares to a total of $\$ 1.36$ billion being paid to families in the 2004 tax year (before WFF). WFF amounts reported here are as at the September 2009 update to the linked MSD/IR datasets.

2. 'Income-testing' is a way to target financial assistance to those families most in need.

3. Linked IR/MSD data beyond the 2008 tax year was not available at the time the analysis in this paper was done.

4. In this paper, 'families' refers to WFF recipient sole parents and couples with dependent children. It does not include singles and couples without children in receipt of Accommodation Supplement. 
5. WFF recipient and entitlement numbers presented in this paper may differ to those published elsewhere due to the rules applied to form the EMTR analysis dataset.

6. Unless specified otherwise, all references in this report to particular years are tax years. For example, the 2008 tax year covers the period 1 April 2007 to 31 March 2008.

7. Social Assistance (New Work Tests, Incentives, and Obligations) Amendment Act 2010.

8. Cabinet Minute (04) 13/4. See: http://www.msd.govt.nz/documents/about-msdand-our-work/work-programmes/policydevelopment/working-for-families/cab-min--04-13-4.pdf.

\section{References}

Karabegovic, A., Veldhuis, N., Clemens, J. and Godin, K. (2004). Do Tax Rates Matter? Fraser Forum, July 2004, pp13-16. Fraser Institute, Canada.

Ministry of Social Development and Inland Revenue (2010). Changing Families' Financial Support and Incentives for Working: The summary report of the evaluation of the Working for Families package. Ministry of Social Development and Inland Revenue, Wellington: New Zealand.

Perry, B. (2009). Non-income measures of material wellbeing and hardship: first results from the 2008 New Zealand Living Standards Survey, with international comparisons. Working Paper 01/09. Ministry of Social Development, Wellington: New Zealand. 